\title{
Middle East and Southeast Asian Refugees in Canada and Finland: Case Studies in "Mature" and in "Incipient" Multiculturalism
}

\author{
Kathleen Valtonen
}

\begin{abstract}
In this article a case study of resettling Middle East and South Asian refugees in the Metropolitan Toronto area is presented and juxtaposed with a parallel study conducted in Finland. The main strategies for labour market participation in Canada were education, "volunteering" and networking activity. The agency principle was pronounced. Interethnic accord is evident at individual level, while at the group level of collaboration it is more elusive. The large size of the communities and Canadian multicultural policy allows for a decentralized style of intra-community activism, but in Finland, the mode of issue-focused civil and political activism across groups could enhance participation of small communities.
\end{abstract}

\section{Précis}

Dans cet article, l'étude du cas de la relocalisation de réfugiés du Moyen Orient et du Sud-Est Asiatique dans la région métropolitaine de Toronto est présenté et mis en parallele avec une étude similaire menée en Finlande. La principale stratégie de participation au marché du travail au Canada sont l'éducation, le volontariat et les activités de prise de contact et de constitution de réseaux. Les principes de l'agence sont formulés explicitement. L'accord inter-ethnique est évident au niveau individuel, mais plus évanescent au niveau de la collaboration collective. Au Canada, la vaste dimension des communautés et la politique multiculturelle canadienne encouragent un style décentralisé d'activisme interne à la communauté. En Finlande le type

Kathleen Valtonen, Ph.D., is a researcher at the Department of Social Policy, University of Turku, Finland. She is currently conducting a study on how labour unions and employer associations influence immigrant employment in Finland and Canada.

\begin{abstract}
d'activisme politique et civil arienté vers des questions spécifiques pourrait permettre une accentuation de la participation des petites communautés.
\end{abstract}

\section{Introduction}

Changes in migration flows during recent decades are affecting countries like Finland, which are no longer on the periphery of routes, as well as the more traditional countries of immigration such as Canada. There has been a much wider diversity of areas of origin of migrants and refugees, who come from cultures which were hitherto unfamiliar to the receiving societies. Under the auspices of humanitarian immigration in Finland, groups of very diverse geographical and cultural origin have been resettled during the previous decade. In Canada, the range of diversity in immigrant groups rose with the 1967 Immigration Act which marked the change in immigration policy away from Eurocentric bias to a universalistic and non-discriminatory direction. The ongoing responsibility of resettling and integrating new minorities is a challenge to policy-makers and publics in the receiving states.

In this article the integration process of resettling Middle East and South Asian refugees in the Metropolitan Toronto area is examined, using case study methodology. The study is basically an exploration of the integration process. The findings are discussed in the light of a parallel case study conducted in Finland during the same period, introducing a comparative dimension in the latter part of the article.

The frame of analysis for integration is societal participation. Societal participation as a conceptual framework for integration, is broad enough to capture into the one construct, central spheres of integration, and thus to lay the basis for a holistic picture of the phenomenon, which is an aim of this study. Societal participation refers here to the participation of refugees in the economic, social, cultural and civil/ political spheres of the resettlement society. Societal spheres represent a comprehensive matrix for investigation, but they are not discrete participation areas. In order to facilitate investigation, they are collapsed into the following participatory arenas: labour market participation and related educational activity; social interaction; acculturation (twoway cultural integration between the resettling groups and the majority society); and civil/political participation. ${ }^{1}$ Societal participation can also be conceptualized as "institutional participation," or participation in the formal and informal institutions of the surrounding society.

Participation in the above sense, constitutes objective aspects of the integration process. In order to explore the subjective, or life quality aspect, participation is examined in the present study in relation to the subjects' self-reported goals. It is an assumption in the study, that the gap between goals and actual participation is an indication of life quality or its absence. If participation is harmony with goals, I assume this to be an indication of life quality in that integration is proceeding in a manner satisfactory to the resettling persons. On the other hand, serious inconsistency between participation and goals would indicate an unsatisfactory condition and hence poor life quality. The gap between goals and actual conditions has been found to be a good predictor of life quality (see Ross, Eyman and Kischuk 1986). In this study, participation is understood to be a phenomenon corresponding to "actual conditions."

\section{Theoretical Framework and Constructs}

Integration theory deals with a very complexphenomenon, and is necessar- 
ily multifaceted. Integration can be seen as proceeding along cultural and structural dimensions. Cultural integration denotes cultural exchange or acculturation, while structural integration is a term used for institutional participation, including a degree of assimilation into the formal institutional structures of the receiving society (most frequently the economic and political/civil) (see Kallen 1995, 152-62). The above conceptual matrix is roughly co-terminous with the analytic framework of economic, sociocultural and political/civil spheres used here. However the present participation concept brings to the study a more 'actor' centred focus.

From a social-psychological perspective, Berry (1996) identifies two criteria for integration: retention of cultural identity and the establishment of ties with outgroups. These criteria are embedded in the acculturation and social interaction aspects of scrutiny in the presentstudy. In thecurrentintegration discourse, the right of resettling individuals and groups to retain their cultural identity is hardly contested. However, with the possible exception of officially multicultural societies, the retention of culture and ethnocultural identity may in practice be feasible only in informal circles. Harrell-Bond (1986, 71) has proposed that integration is a "situation in which host and refugee communities are able to co-exist, sharing the same resources-both economic and social-with no greater mutual conflict than that which exists within the host community." While HarrellBond's definition applies mainly to countries of asylum in the developing world, this author raises the important question of competition over resources in resettlement society, and indirectly, that of community and intergroup relations, which are salient issues in integration research.

In this study, I adopt a working definition from Breton (1992), in which integration refers to the process by which immigrants become part of the social, cultural and institutional fabric of society. As is practical in the qualitative methodology, the definition chosen is broad enough to accommodate the range of anticipated participation phenomena, as well as others that may arise in the course of the research. Breton (1992) has also brought out the importance of individuals' and communities' capacitybuilding activity which is often crucial to the integration process.

\section{Methodology}

The research method in both the Canadian and the Finnish case ${ }^{2}$ was based on semi-structured, in-depth interviews of $1 \frac{1}{2}-3$ hours in length. Theinterview questions were open-ended, covering issues related to the main fields of participation, such as educational and professional background; language skill; labourmarket participation and employment strategies; support and interaction networks; relations with majority society; organizational activity, civic and political activism; and cultural integration. The sequencing of themes was flexible. For the subjects, the interview relationship was largely one of the sharing of resettlement experience that was constantly going through a process of collective reflection in the communities. The dialogue yielded information on individuals' situations and, especially in the Canadian case, drew upon the communities' cumulative immigration experience. The perceptions and meanings given to phenomena had a robustness derived from the common experience. The dialogue was, in this way, often lifted out of the personal perspective to the social one. The case in Canada may have lost some "uniqueness" in this medium of general reflection. There was a slight trade-offbetween "uniqueness" or the intrinsic quality of purely individual experience, and deliberation at a developed stage. In any event, this was not disadvantageous in medium of qualitative methodology. The procedure of "coding" entailed fracturing and reorganizing of the raw data. The findings are presented according to participation area.

The interviews were conducted in fall 1994-spring 1995. The field work in Toronto extended over a period of nine months and involved participation in some community activities and partici- pant observation. In addition I collaborated on this site with six research informants who were themselves settlers of some other national origin, but possessed considerable experience in resettlement work with the communities examined in the study. The field workin Turkubenefited from my previous experience in settlement work with the communities under study, and subsequent periods of participant observation.

In the Toronto Metropolitan site, the case comprised 24 individuals originating from Islamic countries in the Middle East and South Asia (Iran, Iraq and Afghanistan). The second case resettling in the Turku city environs in southwest Finland, comprised 29 individuals originating from countries in the Middle East (Iran, Iraq and Kuwait). From the research perspective, the dominant characteristic in both cases is their refugeebackground. They had arrived in the context of involuntary migration and in the aftermath of complex sociopolitical displacement phenomena which have remained largely unresolved in the interim settlement period. The cultural gap in resettlement is, in both cases, deeper than if resettlement had been possible in neighbouring countries or in the region of origin. In the Finnish case, which had arrived in the early nineties the subjects' period of residence was between one and five years. In the Canadian case, eleven subjects had resided under five years, but thirteen of the group had been resettling over a longer period (5-10 years). The spread of the subjects' residence period in Canada was roughly similar in the national groups which all included persons who had arrived nearly ten years previously as well as those who had comemore recently.

Even though origin in Islamic society is an underlying linking feature among the subjects, there is considerable variation among individuals in the adherence to, and practice of Islam. The subjects themselves have emphasized religious and other innate diversity in communities. For example, the resettling groups under study here include persons who are highly educated, of "middle class" urban backgrounds, as 
well as individuals for whom resettlement into cities in Canada or Finland, also represents a "rural-urban" transition. The weight of the investigation is, however, upon the integration issues and tasks which they face as newcomers and minorities in the resettlement environment ${ }^{3}$. The populations under study displayed strong intra-group cleavages along political, ideological and confessional lines. Intra-group differences are probably of the same order as inter-group variation, including ethnonational variation, a circumstance which argues against using purely ethnonational characteristics as sampling criteria.

\section{Canada and Finland as Settlement Countries}

Both Finland and Canada are advanced welfare states that include immigrants as members with the same rights to social welfare as other citizens. Settlement into this type of society means that a basic level of financial security and services offset, to some extent, the risks of unemployment, sickness, disability and old age. At the time of the study, the labour market situation in both countries was difficult.

Immigration policies of Canada and Finland are different. Organized immigration has been seen as part of the strategy for building the demographic and economic base in Canada, which reports one of the highest levels of immigration in the world (Thomas 1994). Immigration policy that was liberalized in the late sixties, promotes a socio-economic cross-section of immigrant admission, with selection procedures emphasizing employability. In recent years, the annual immigration figure has been around 210,000 persons, including all classes of immigration. Attention has been drawn in the mid-nineties to the changed profile of the flows, brought about by high levels of family reunification and sponsorship, in which selection criteria cannot be uppermost. The sponsorship program has facilitated the reunification of wider kin circles, conditional upon financial obligations being met by the sponsoring person over an agreed number of years.

In Finland, there has been no period of foreign labour immigration. The utilitarian aspects of immigration have not been discussed a great deal, as Finland is not currently in need of additional labour force. The level of unemployment during the recession of the 1990s, has been around 16 percent. Immigration policy remains restricted or "controlled," except within the context of the European Union, of which Finland is a member. On the other hand there is a substantial flow of "return ethnic migration." In addition to regular return flow, persons coming from the area of the former Soviet Union who are of Finnish origin, are entitled to reside permanently in Finland. The annual rate of intake is around 2,000, and since 1990 approximately 15,000 "returning ethnics have already settled in Finland. Non-European immigration arrives mainly within the category of humanitarian immigration, which is organized under United Nations High Commission for Refugees (UNHCR) and state auspices. The refugee resettlement program is ongoing. Around 1000 persons are received per year, including quota, humanitarian and "spontaneous" categories. ${ }^{4}$ Since 1973 , when the first group of Chileans were resettled, about 15,500 refugees have been received, the main countries of origin being Vietnam, Somalia, Iran, Iraq and the former Yugoslavia. Refugees form approximately 0.3 percent of the population, and for them there are clear provisions for reunification of immediate family members of the two generation family. Immigrants form 2.2 percent of the population, the main groups originating from neighbouring countries such as Estonia, Sweden and the Former Soviet Union. This figure includes "returning ethnic" migrants.

\section{The "Canadian" Case}

In Toronto, interviewees were accessed through numerous community organizations and contacts. The target group was purposefully sampled, ${ }^{5}$ and included six persons involved in settlement services and three who were volunteers in the same sector. In addition to their own personal experience of refugeedom, these persons were able to share valuable insights and experiences from the communities they served. Data were given an added dimension of community as well as personal perspective. In using direct quotations, I have altered thenames of the subjects to maintain confidentiality.

The target group is not representative of populations from which they are drawn, and findings cannot be generalized to the whole entity. However, as in qualitative research, the findings can deepen our knowledge and generate insight into the complex processes involved in refugee settlement and integration, in this way, assisting theorybuilding.

A brief profile of the target group's social characteristics will facilitate contextualizing of the empirical data. Half of the subjects were male, and half female. The age range was $20-65$ years, almost the entire span of labour force eligibility. The educational background of this group was strong: 14 persons had reached high school level, or higher education; five had intermediate level and five elementary level schooling. The unemployed were in the majority (14), while among the employed (10 persons), six were connected with settlement service provision. One-third of the subjects were still awaiting family reunification. The group was roughly divided between those who had been resident between one and five years, and those who had resided for longer periods, between five and ten years.

\section{Participation in the Economic Sphere}

In investigating the subjects' labour market situation, I also sought information on their educational and professional experience prior to resettlement, and on the employment strategies which they used. In this group with a relatively higheducation level, ninepersons had already had a considerable amount of professional and working experience in their home country. Of these, five were employed. However, in the target group, none of the ten em- 
ployed subjects had found occupations corresponding to their qualifications and experience. Some had found work that was somehow related to their field of expertise/experience, but had experienced severe occupational downgrading, as for example, from electrical engineer to electrician, from owning a footwear enterprise to shoe repair. Others had managed to relocate into another area. Of the thirteen who had arrived earlier, seven were in employment, but they had not been able to achieveover time, the required degree of upward professional mobility to reach equivalent socio-economic status. Thus on the basis of these data, educational/ professional background and longer length of residencedonot seem to have had significance for labour market entry, or for upward occupational mobility.

It is evident that employment, of whatever kind, denotes a tangible outcome of integration effort. Those in employment had in different ways achieved financial independence and the active/productive role and status that participation in the labour market brings although admission to the labour market was attained at the price of underemployment, or in some instances, relocation. Professional relocation was not reported as a disadvantage. The interviewees who were employed in the human service and settlement field felt that they were at least in useful roles and that they were engaged in meaningful work.

At the time of data collection, the labour market conditions in the resettlement society were very difficult. Facing a situation of job scarcity, those whohad not yet located work, were, like their local counterparts, having to engage in innovative and long term strategy to gain labour market admission. The main strategies involved activity in $e d u$ cation (such as training courses and further education), "volunteering" in the public sector institutions (e.g., hospitals, schools) and networking in the job search.

Training courses were considered by the subjects to be effective, not only on account of the additional expertise gained but also because they could provide contacts to the labour market. The ability to access a course appropriate to their specializations, and which would place them in a better position in the job market, was highly valued by subjects. The course teacher, too, was seen to function as a concrete link to the labour market. Through his/her instrumentality, valuable information, tips and contacts were passed on to thestudents who would otherwise, as newcomers, have no avenue to specific and current information.

Through volunteering, or voluntary activity, the formal merit of work experience in the Canadian setting was obtained. In one sense, relations of interdependence with the resettlement society became reinforced, as individuals offered their time and services free of charge in a useful way to the community. The engagement in volunteering activity was felt tobe "two-way" and at times strongly binding. A female subject, related that she assisted a terminally ill co-ethnic during her period of illness at the hospital. She explained her role and the nature of the assistance she could render: "When one is in crisis, one needs to communicate in one's own language. In one's mother-tongue, it is possible to convey so much more." Volunteering thus involved people in a special way in the community, apart from being a means of acquiring the formal merit.

Individual networking for employment opportunity was heavily emphasized in the settlement services, especially by immigrants with longer resettlement experience. In the well established Iranian community, for example, accumulated practical experience in thejob search and labour market participation, when shared, can be an empoweringelement fornewer members of the community who are seeking employment. Among the subjects, the agency principle (the efficacy of the individual to influence his own environment, and "take charge" of his own life situation) seemed to be uppermost in the job search. One settlement worker described in detail how he instructed a timid client on finding his way to, and approaching officials and potential employers. These skills are also focused upon in orientation courses for immigrants. The preliminary labour market stage was clearly regarded as one of goal-directed activity. Theemployment strategies in the communities, and the emphasis on "agency" in settlement services, suggest that Canadian multicultural policy, in explicitly underwriting the membership of immigrants in the society, may confer at the same time, an implicitmandate on them to seek out and pursue opportunity on their own initiative.

\section{Canada and Finland Compared}

Continuing education and labour market training have come to occupy a central place in labour market relations both in Canada and in Finland. Persons of labour force age are becoming used to mobility and re-training in the job market as intrinsic phases and preconditions of labour market participation. In this regard, the dimension of "capacity building" comes into question in the integration process (Breton 1992). While this condition applies to the majority society and immigrants alike, the terms of participation are not equal. As mentioned above, locating employment at a level corresponding to qualifications is a problem which is often encountered by resettling individuals. Several of the subjects were encountering difficulties in transferring their professional skills and experience, even though accreditation procedures have been established.

A level of labour market participation that does not correspond to qualifications and experience constitutes a leakage of human capital for the receiving society. For resettling persons of higher educational background, requalification as an integral part of relocation, naturally postpones the development of labour market ties. A graver problem arose when age and the family situation of subjects would eventually rule out their possibility of undertaking several years of equivalency studies and practical training. A serious hurdle in the target group was financing since opportunities for ob- 
taining support for studies had shrunk, and was in most cases not available. Subjects pointed out that for persons without sufficient economic resources or for those with dependents, lengthy accreditation procedure was not a realizable possibility, unless they could combine work and study with family responsibility. In this target group, subjects with a strong educational background had invariably tried to become requalified. Somehad had to give up for personal or family reasons, others were still in the process of re-acquiring qualifications or were seeking skills in other fields, such as those individuals who were volunteering in the social services.

Personnel in the ethnospecific settlement services (orientation and settlement services organized by the immigrants as part of the multiculturalism system) expressed concern over the fact that immigrant professionals' prospects were often low in comparison with that of local professionals, materializing not unusually in gas station or convenience store jobs, which are in general the temporary starting point for local youth. Settlement worker Kazim, described the difficulty:

\begin{abstract}
A young person can perhaps study for the additional qualifications required. But an older person with a family to support, cannot afford the time taken for exams and studying. They give up and take whatever employment is available. For financial reasons, they drop out of their career.
\end{abstract}

The predicament of resettling professionals is exemplified in the case of immigrant physicians in Ontario. The "uncertain quality" of Foreign Medical Graduate's(FMG) professional education has been raised as a core argument in the prevailing stand on the limited entry rate of FMGs into professional practice. ${ }^{6}$ Limited internship opportunities as well as underaccreditation also raise the threshold to employment. ${ }^{7}$

In Finland, a similar situation exists among, e.g., engineers and doctors, although the resettling populations are smaller. The unemployment rate of immigrants has been three times higher than the average, and is marked in the groups under study here, which arrived more recently and are more highly educated. Trained teachers in the Finnish target group had been teaching in the refugee camps. They cherished the goal of finding work or at least a place to study in Finland. The process of gaining admission to higher education institutions was not simple. One subjectstated: "Ihad a differentidea of Scandinaviathe reality is that there is no work... and the opportunities to study depend on so many conditions." The same subject explained that he (and others like him), had been unable to continue their university studies in their home country, because they had been disqualified during the political screening when officials had delved into the political past of all their kin.

One subject, Maryam, had a background in civil engineering in Iran. ${ }^{8}$ She was one of those who had invested considerably in their professional training, and was steadfast in seeking a way to become requalified and utilize her human capital appropriately. She expressed it this way:

After the first three needs, when one has already a "quiet life": one is free, there is enough to eat and one has a home, there are other things to attend to. Education has not been handed on a silver platter, one has made an investment in it for a better

life, and it cannot be thrown away.

The employment objective of the highly educated would demand extra manoeuvres in resettlement. For these persons, resettlement has brought the "quiet life." Although security is highly valued, it is questionable whether it can continue to generate life quality indefinitely and compensate for a gulf between professional goals and reality.

\section{The Afghan Predicament}

Unemploymentamong Afghan subjects in the target group, signified a very deep gulf between priorites and goals. Dependence upon basic welfare type allowances, meant that they were lacking resources to render material assistance to kin and close relatives in precarious circumstances in first asylum and in zones where civil strife still endanger life and limb. The dilemma of the Afghan subjects is common to other refugees whose close circles are still facing problems of survival in the home country or in first asylum. Fatima explained:

Everyone has brothers, sisters or parents in the countries of asylum. International assistance has been stopped, since Afghanistan is considered safe for return. They are without work, without food, without medicines ... If they were in a camp, or under international protection, it would be a very different situation from what it is now. But the authorities think that it is time for Afghans to return and have stopped assisting them ... When there is no international assistance, refugees become weaker and are vulnerable to diseases like malaria. I received a letter recently from my brother. He writes for help, no matter how small ... their situation is getting desperate ...

Subjects felt responsibility for assisting their relatives. They wished also to sponsor them to the country of resettlement. Both these tasks hinge upon the ability to generate income from work. Unemployed persons are not accepted by authorities as sponsors as the former are not in a position to comply with the conditions of sponsoring, i.e., to assume financial responsibilty for the sponsored relative/s over the prescribed number of years after arrival. The frustration and anguish at not being able to alleviate the situation spring from the culturally based family cohesiveness and extended kinship network solidarity (see Hatch Dupree 1990) in the Afghan community. Integration and participation in this community, emerged as a process with collective as well as individual ramifications. The order of resettlement goals is reversed when the subjects' own secure situation is taken intoconsideration. As a spokesperson for the community explained, "We put first our parents, our children, our nieces and nephews, our brothers and sisters. Our ways are not self-centred." Fahima, a young mother said:

I will do any kind of work. We realize that we are immigrants. We are young, we can do anything and are willing to take whatever we can get 


\section{... but we seem to have no chances at} all.

The interviewee quoted above spoke for a group of others who have been hoping and trying to sponsor some of their close relatives out of first asylum conditions for over twelve years. The scarcity of jobs was compounded by their lack of language skill. Being able to access language training, in turn, depended upon the availability of childcare facilitiaties. The situation in this group indicated that the existing scope of settlement and other services was not adequate for their empowerment in the integration process. For some women who were wanting to work or attend language courses, the inaccessibility of child care facilities, combined with travel distances ruled out their chances at the time.

\section{Participation in the Socio-Cultural Sphere}

In this area of participation, the interview questions relate to intra-community relations, inter-group relations and out-group relations in general. When asked about inter-ethnic relations, subjects were never at a loss to reply. One subject proposed that "the weight of the communities automatically puts all nationalities on an equivalent footing as Canadians, since neither the AngloSaxons or the French are in the vast majority." In urban immigrant concentrations such as Toronto, the fact that even smaller groups are of substantial size, reduces majority-minority bias in relations. A type of official cultural equity among groups has been negotiated through multicultural policy's recognition and legitimization of the place of distinct ethnocultural entities within the nation. ${ }^{9}$ This explicitly stated inclusion of minority groups is valued by resettling communities and minorities such as, e.g., Assyrians whose status in their own homeland has been problematic.

For another subject, the initial impression of Canadian multicultural society remained vivid:

It is difficult to explain how it was when I first came to Toronto ... it felt like an ocean of different people. I had lived in Iraq where I had always been part of the society. In Spain [the subject's country of transition before resettlement in Canada] one would still feel different after living many years there. For example, if I went to church, I could not understand anything at the beginning, as I did not at first know Spanish. I felt as if I were deaf. A person needs somebody with whom to talk, and especially in your own language. Without this one can become afraid.

Communities of viable proportions, such as those that have developed in Canadian cities, offer a liberating effect in many areas of participation. There is scope for choice in informal interaction as well as in the developing of formal associations. In national groups under study, in which political, ethnocultural and other cleavages persist, it is not possible to achieve cohesion at overall group level. A degree of cohesion is generally achievable at the micro-level of sub-groups and circles. (See Valtonen 1994; Gold 1992 for similar findings in other resettlement countries). Large communities offer scope for intra-group structure, whether they be spontaneously developed informal support circles, or formal associations with differing missions. As a rule, the decentralized nature of community organization in Toronto seems to have grown out of the imperative of establishing several focal points in each community, to accommodate the intra-group variation along sociocultural, confessional, political, ideological and other lines. Multiculturalism, or the cultural "mosaic" model, has been developing for over two decades in Canada. Over time, the initial goal of inclusion of diverse cultures into the national fabric has evolved also into anti-racism and equity promoting action. The decentralized pattern of community organization represents a blueprint for activism and participation on a broad front. It reflects the heterogeneous composition of ethnic groups and seeks to address the spectrum of their resettlement needs and aspirations. In this sense, the present style of activity can be seen as the modus operandi of the multicultural mosaic.
Multiculturalism is not an easy phenomenon to track from policy into implementation. For example, the overcoming of sectarian attitudes and intra-ethnic cleavages has not been systematically addressed by multiculturalism in Canada except through the ethos of inclusiveness that characterizes multicultural programs. Nonetheless the officially declared principle of "unity in diversity" has functioned in legitimizing a place for all ethnic groups and in introducing order and community pride to a large scale resettlement program (see McAll 1990 for a fuller discussion of Canadian multiculturalism).

In a culturally plural urban centre like Toronto, outgroup interface is multifaceted. Social interaction as well as acculturation is happening on many fronts. As one subject described,

The multicultural situation has brought together people of many backgrounds and cultures. We do things together, we meet every day and slowly learn to know each other better. We may value this one for his honesty, that one for his friendliness, and so on, not only for the similarity of background. Understanding increases on another basis. We find other commonalities. Multiculturalism is, in a way, a success in that we live in one place, we are "forced" to attend the same schools and are "thrown in" with each other. We can relate to each other, we find that we are all Canadians. The citizenship certificate or paper does not in itself accomplish this.

The interethnic accord, which is one of the central aims of multiculturalism, is thus evident at individual or personal level, even though at the group level of collaboration it may be more elusive, and not easily realized through formal measures. Survey data from a study commissioned in 1991 by the Department of Multiculturalism and Citizenship have indicated a direct correlation between cultural pluralism and tolerancelevel in the community (Lindström 1995).

Separation in the family unit of involuntary migrants profoundly disturbs the most basic relationship network. In 
the target group it was observed that prolonged periods of waiting for family reunification were usually very dysfunctional for the adjustment and integration process. One subject with experience in settlement service stated that in some cases, integration would begin in earnest only after five years, if such was the period before the "nuclear" family could be reunited. Family reunification is naturally the fundamental priority in cases of extant family separation. Problems in this area are psychologically enervating with the result that progress towards full participation in the surrounding society is obstructed.

The subjects cherished autonomy in selecting their close circles among coethnics. Such behaviour was explained as a security precaution in divided communities. In the immediate aftermath of civil conflict in the country of origin, even co-ethnics cannot be trusted indiscriminately. Underlying the very purposeful selection of circles is possibly a wish to avoid social control of the wider ethnic community. A select reference group can be a socially liberating milieu for interaction. Individuals may be making an effort to define themselves in social rather than in ethnic terms which tend to subsume individuality into a cruder category. This feature of "social self determination" is also very evident in the intra-group interaction dynamics of other resettling groups,e.g., Vietnamese (Valtonen 1994; Knudsen 1991).

\section{Cultural Retention and Acculturation}

The maintenance of culture and the organization of cultural activity is not difficult in large ethnic communities. Moreover, multicultural policy in Canada formally supports ethnicbased activity, not only from a "folkloric" aspect, but also in the practical context of so-called "ethno-specific" settlementservices, organized by ethnic and other community organizations. Ethno-specific settlement services are developed in the large population centres where there are concentrations of immigrants and immigrant communities. The ethnospecific sector programs have their own niche in the social service network, focusing on the whole field of settlement, while bridging to the mainsteam service network. They are administered and implemented by persons who have themselves come as immigrants or refugees, and can, in a singular way, address the needs and problems of newcomers on the basis of their experience and skills. Workers from the communities can exploit their language skills and cultural competence in addition to professional skills for settlement work which are acquired through training courses.

Ethnospecific organizations in large cities have developed a wide range of services, including counselling, advocacy, referral, information dissemination, workshops and training in life skills, language courses etc. The quality of service is enhanced by communication in clients' own languages (as needed), as well as by appropriate ethnocultural approaches and methods when the need arises. The ethnospecific sector constitutes a level of institutional completeness in that some of the community's most crucial needs can be met in the medium of their own culture and institutions.

The danger of ethnic organizations encapsulating their ethnic clientele is countered by the availability of service alternatives. In sizeable ethnic communities, there are usually a few agencies. Settlement agencies can also function on an inter-community basis, targeting their services across ethnic, cultural or linguistic groups, as for example, The Arab Community Centre of Toronto, Southeast Asian Services Centre. The multicultural approach in service provision seems tobecomingmore common in ethnic community organizations. The other service alternatives include mainstream (municipal) agencies and focused resettlement services, e.g. the Immigrant Womens' Job Placement Centre, Neighbourhood Centres etc. Subjects used the ethnic services selectively, and, because of the range of options, were not a captive clientele.

Some appraisal of the ethno-specific sector is in place as it is one tangible manifestation of Canadian multi- culturalism policy as it has proceeded from the "folkloric" culture-emphasising stage toward programs that profess anti-racist, antidiscriminatory thrust and empowerment objectives. The sector, a quasi-public service area, has been developed in a niche that has been carved out for minority institutions. Services as well as service positions and professions have been generated. The ethno-specific sector is characterized by its employment of immigrants. This can bedescribed as a form of positive action which promotes empowerment through proportional "representation" at institutional level. ${ }^{10}$ In another way, it also constitutes a direct measure for facilitating immigrants' participation in the economic sphere, as it has generated services that strongly support users' strategies to the labour market, e.g. courses onjob interview techniques, telephone negotiation, $\mathrm{CV}$ writing etc.

From another utilitarian aspect, the sector has brought community assistance mechanisms into the formal professional sector, without losing the spontaneous community level dedication. The commitment of subjects in this sector are based on meaningful relations with, and as, community members. This not only enhances service, but also permits ethnic personnel to contribute effectively to the resettlement of their own communities.

The ethno-specific sector, as well as multiculturalism itself, has it critics. Ethnocultural settlement services are limited in scope to immediate tasks of settlement and seem to lack the capacity to assist, for example, those who are negotiating the "gates" of the professional associations and labour market. The ethnospecific sector is not seen to be at the cutting edge of critical integration issues of power and social inequality, although they do give voice to minority opinions. Whether their mandate extends to those areas is not clear. The growth of the ethno-specific sector has been accompanied by the danger of too much emphasis being given to the ethnic profile of resettling populations and the risk of unduly competitive relations at the inter-community level. In practice, the trend toward cross-cultural and 
multiethnic service moderates the potential for conflictural configurations.

\section{Political Participation}

Subjects were asked about participation in party politics and ethnic-based political activism. There were few indications in the target group of actual participation in community-based pressure groups or in other forms of political action. There were strong indications that a background of political activism would not necessarily furnish a basis for activism in resettlement. On the contrary, in the Iranian, Iraqi and Afghan groups understudy, a previous background of political activism and commitment tended to limitsharply the capacity for interconnections in the community as a whole.

Political activism in a resettlement context would call for refocusing on locally salient issues and reworking of affiliation. Activism requires familiarity and first hand experience with the sociopolitical field before interest can be transformed into aggregate demand, involvement and action. Questions of representation and interest mediation would also need to be negotiated on the basis of some level of intra-group consensus, which seemed to be an elusive quality. Nonetheless, at the time of the study, several subjects with longer resettlement experience, had made enquiries or were otherwise keeping themselves informed of interest-based activism initiatives in the communities.

In the target group, persons with interest in participating in electoral and extra-electoral political activity, indicated that they sought, or would seek, direct affiliation to mainstream parties. The data indicate that these individuals are making independent choices on their style of civil and political participation. Many would prefer not to be confined to ethnically based channels and immigrant interest groups, even though such inter-organizational fora do exist and attract participants.

\section{Gender}

An issue brought up by some of the subjects and settlement workers was an observed difference in mens' and womens' coping capacity in the resettlement groups under scrutiny here, as well as in other resettling groups. For example, occupational downgrading was reportedly often much more unacceptable for male spouses than for female. The reported gender difference in integration is discussed here on the basis of case data from the target groups under study. This phenomenon is not identified solely with these particular populations, especially in the context of thehigh degree of heterogeneity in Middle East and South Asian societies. Moghadam (1993, 6-10) emphasizes the diversity within the Middle East region and within the female population:

The Middle East is not a uniform and homogeneous region. Women are themselves stratified by class, ethnicity, education, and age. There is no archetypal Middle Eastern woman, but rather women inserted in quite diverse socioeconomic and cultural arrangements.

In the same vein, Obermeyer (1995, 371) states that there is a good deal of evidence from many regions of the world suggesting that societal definitions of women's roles and reproductive rights are affected more by local and international politics than by religious doctrine as such.

In discussing aspects of role change and continuity in resettlement, female subjects pointed to the fact that the participation of women in public life had been increasing incrementally in their own countries prior to the events and social upheaval that led to flight. In Afghanistan, women had started to take part in public and working life as doctors and teachers, and in professions that were considered "appropriate" in the context of family responsibility. In Iran women were allowed to work outside of the home in e.g. teaching and nursing fields, and with increased female participation in education in the early 1970s, women could pursue studies in high technology areas and access employment in their own specialities. The evolution of the women's societal and public roles had begun in their countries of origin prior to resettlement.
With regard to adaptation problems and coping resources, a settlement worker, who had worked with "difficult" cases, stated that she had found that

Women are more flexible ... for example, a woman with Ph.D. will goto work in a donut shop, or do sweeping rather than stay at home helpless ... Women are [working] in the coffee shops in Scarborough. They go out and bring some money in. At home when the woman is the one working and bringing in the paycheck, it is not appreciated. The man resents his loss of status and role, he loses his self esteem and feels worthless.

The greater difficulty in "settling for less" among males was described by another subject as follows:

Problems of family life arise since the culture of equality in Canada is hard for men to swallow ... When people arrive they are so happy and glad to be in Canada; then they are faced with the actual situation they are in. Their dreams come crashing down, they experience loss of confidence and depression. I have seen it many times ... the process of elation, then dejection and depression and powerlessness.

Some women have a lot to bear. They have their own problems during resettlement, but in order to carry on the family life, they keep their own problems to themselves. They cannot speak out since the family is already going through so much. Some cannot cope in the long run, and the family then is in crisis.

Freire (1993) has found similar configurations in the Latin American refugee population in Toronto. This author argues that for Latin American women, the central and most meaningful life task of caring for their families is a constant throughout pre-resettlement, exile and resettlement. ${ }^{11}$ Exile is thus a process that is experienced differently by men and women.

From the Finnish experience, it has been observed that women's adaptation problems can be alleviated by role continuity in the domestic sphere. In addition, however, their entry into wider resettlement society is formally 
facilitated by universal access to language and labour market placements and training courses. In cases where women had previously had more secluded societal roles, the change can be experienced as positive. This is often in contrast to role changes of the male head of the family who may face indefinite periods of unemployment or misemployment, and a consequent shrinking of both formal and familial social roles. On some occasions, strong collective orientation to integration challenges has been an asset. If the family can perceive the uneven opportunity structure as a challenge in common, this approach may soften individual trials (Valtonen 1995).

Freire (1993) proposes that the basis of coping mechanisms for women lies in their ascribed socio-economic status, in which they are accustomed to having fewer opportunities and are assumed to be able to survive and cope for the family. Freire's (ibid.) thesis is relevant to this study. In many societies, including the societies of origin of the target group, women's problem-solving techniques are often honed in less than optimal circumstances, and they would be used to manipulating and maximizing a more limited range of strategy alternatives. Paidar $(1995,335)$ writes in the same vein on societal participation of women in Iran, which took place despite limitations. Although the Islamic state did not ban women's employment outside the home,

State legislation did encourage women to stay at home; what proved more inhibiting to women's employment was male prejudice and negative attitudes operating at the local level ... Meanwhile, women continued to use the opportunities open to them for supporting themselves and their families and contributing to the economy. (ibid.)

A source of insight into this issue is found in black feminist thought even though the latter is largely located in the context of the experience of AfroAmerican women. Hill Collins (1990) outlines the notion of empowerment through self knowledge, even in conditions that severely limit the individual's ability to act. When empowerment is not forthcoming in the context of community, "such change can also occur in the private, personal space of an individual woman's consciousness" (ibid., 111). The following statement of one of the subjects illustrate this empowerment strategy:

My husband will not accept the present situation. Iranians have high expectations. I have tried to tell him, "Do not swim against the current, as you will expend yourself. If you swim with the current it will be possible to find ways to get through this situation, somehow or other" ... he is expecting that the clock will be turned back and the former way of life will be restored.

The concept of emancipation is also useful in this context. Refugee resettlement and integration is generally seen as embodying a marked aspect of emancipation, in that human rights, including civil rights, are restored, and the resettling persons gain "citizenship"12 in the new society. For many individuals, resettlement means a degree of emancipation in one area but possibly setbacks in another. The attainment of civil liberty and freedom can be accompanied by restraint in another sphere, e.g., the professional sphere. Integration, as a process towards eventual full participation in resettlement society, implies the overcoming of barriers in all societal spheres.

\section{Resettlement and Integration in Canada and Finland}

Unemployment was an obstacle to integration across the target groups. Data indicated that locating employment, especially in the area and at the level of qualifications, was a task of the same magnitude for subjects in Finland as for those in Canada. A subject who had been trying for several years to enter the labour market, felt that: "Finns think that immigrants know nothing. It is so easy to underestimate us because we have no chance to show that we can do something and that we have capabilities. What we have is going to waste."

The onset of the economic recession in the early 1990s in Finland seems to have been a turning point in resettlement. It precipitated labour market restructuring as well as high levels of open unemployment, necessitating an approach to resettlement and integration from the perspective of very longterm utilitarian concerns. Finland has maintained the principle of full employment as a core aspect of the welfare state. The high unemployment levels have been addressed in the interim by greatly expanded educational and labour market training programs, while atypical employment alternatives are being discussed and promoted. Deferment of more concrete engagement with society, via lengthy education and training, was difficult for some of the subjects who wished to take a more direct route into resettlement. This is expressed by a young Kurdish man: "I don't understand this system where refugees are taken and put through a couple of years in courses and training before they can be let out into the real world to survive and look after themselves." Data in both sites show that resettling persons are prepared for a period of "capacitybuilding" in the new society, e.g., language instruction and professional equivalency courses. Several looked very positively on the opportunity to participate in what can be seen as preliminary labour market training. However when this period of capacitybuilding was prolonged, and seen to be possibly a futile exercise that would not lead to employment, the activity was felt to be disempowering by the resettling person.

The problem of unemployment and underemployment of professionals in the target groups and in the resettling populations remains to be addressed effectively in Finland as well as in Canada, where resettlement experience is even much longer. Institutional mechanisms and interest group configurations that impact on this issue in Canada have been focused upon in studies by Lam (1996) and Battershill (1992). This problem is one of human resource utilization. Strong educational and professional background have generally been considered to be assets in resettlement. Yet resettling in- 
dividuals with these very qualifications are faced with the difficulty of transferring qualifications and skills, often facing a type of professional disqualification in practice.

Immigrant business enterprise which is a well established avenue to employment in Canada, is also becoming more evident in Finland. For some resettling persons it is one alternative way of coping with "blockages" in the labour market (Lam 1996, 173-74). It constitutes a form of labour mobility, as does the transition to work in the ethnospecific settlement service sector described above. Some individuals with a previous background of entrepreneurship have managed to transfer and utilize their skills in the settlement environment. Others have switched to entrepreneurship, or a new area of entrepreneurship, using an opportunity for self-employment in a tight labour market.

The highly qualified professionals in Canada who have moved into the ethnospecific settlement service field have undergone a type of occupational mobility that is "oblique." In one sense, their having to start over again constitutes a type of occupational downgrading. However, since they have transferred to a new professional field, the direction of mobility has not been downward in a strict sense, but "oblique." The work satisfaction expressed by these individuals indicates that, for them, "oblique" labour mobility had proven to be an acceptable strategy. When asked how she felt about having had to switch careers and about the fact that her training in biochemistry was not used, Farida stated that the change in career was not disturbing, as herwork was very interesting. She said:

One never gets bored, as for example, when sitting working in an office. I had never considered [the social field] ... but I enjoy my work and sometimes wonder how I did not think of doing social science before.

A subject who had simply moved drastically down the scale in his own field, felt more socially disoriented, as exemplified by his resigned comments:
I am not like Canadians, when they worry about trivial things and get upset. I take things as they are ... You see, I have seen how easy I can lose. All I had earned, everything I have spent to come here. I started with nothing. Others aim at having a good financial position, education, the good of their kids. Everything is much harder here.

These findings have implications for policy on labour market insertion of persons with strong professional and working experience, even though from a human resource point of view, "oblique" labour mobility may not be the optimum way to utilize their human resources.

The research findings indicate that an established numerically strong ethnocultural community can be a significant resource for its members. Although the degree of ethnicidentity and affiliation of members varies, members nonetheless can have the benefit of wider information and socialnetworks, links to majority society and brokerage mechanisms generated in large communities, as well as the advantage of a broad spectrum of accumulated experience. The groups in Finland face a different type of encounter with resettlement society, as resettlement experience and in-depth perspective on conditions are still in developing stages because of the relatively short period of adaptation, and numerically smaller communities. Moreover, the demographic imbalance between majority society and small resettling groups in Finland may be one of the prime factors generating social pressure or expectation of conformity to majority culture. One subject's wry comment was: "It is not enough to adapt in that one obeys the law and keeps within its boundaries. One must become Finnish." This was not evident in the Canadian target group, which forms part of a much larger immigrant community.

When newcomer groups are small, as in Finland, there can also be more reluctance to acknowledge and address structural obstacles or blockages to participation. For example, university application regulations for basic degrees, cater to applicants with local educational background, which in practice, has proved to penalize candidates with immigrant background. The effort to make inroads into such policies proves to be very demanding for small resettling minorities.

The different immigration philosophies and policies in the two countries are shaped by their own socio-economic and other imperatives. Admission categories in Canada have included labour immigration, family reunification and sponsorship, selective business migration etc. This makes for community growth as well as a wider social crosssection within ethnic communities. The more humanitarian-oriented policy and narrower family reunification policy in Finland undeniably produces skew in resettling groups, especially that of age and generation. In this respect the resettlement configurations in the two countries vary. The priority placed on family reunification and the ongoing significance of original kinship and close circles is nevertheless very evident from the data in both cases. Through the sponsorship program in Canada, the wider family may also be reunited, the process being subject to different criteria, including that of viable financial status of the sponsoring person. Within thecurrent policy framework in Finland, there is at this time, no scope for rebuilding the wider family entity in resettlement. The presence or absence of kinship circles may have significant effect on the integration process in the long term. This issue would call for further research in order to inform immigration and settlement policy in Finland.

\section{Community Relations}

As expected, the corresponding Middle East groups under study in. Finland reflect cleavage characteristics on politi$\mathrm{cal}$, ideological and other lines that are similar to those observed in the Canadian target group. While the historical or sociopolitical origin of cleavage may be of interest, the aspect of these cleavages that has significance for resettlement, is their persistence, which is an indication of innate diversity and variation within ethno-national groups. There are clear indications that indi- 
vidual settlers prefer to organize their own identity and reference groups against the backdrop of ethnic or ethnonational community membership and to avoid being dwarfed in an overriding ethnic category.

The increasing evidence for lack of cohesion in ethno-national groups (see, e.g., Rachedi 1994; and Gold 1992), calls for re-thinking of settlement program approaches which tend to coalesce around, and target collectivities on the basis of ethnic or ethno-national characteristics. It is obvious that culturally appropriate services offering the possibility of communicating in the mother-tongue, enhance the quality of settlement programs in the early settlement stage and in problem situations that require particularly supportive interventions. Neither does theneed for ethno-specific service components diminish when immigration of particular groups is ongoing, for example, through channels of chain migration, and sponsorship in Canada. However, even in the well-developed ethnospecific settlement service sector in Canada, a multicultural, or inter-cultural principle has come to characterise service provision. This is portrayed in the multilingual medium, and multiethnic/multicultural composition of personnel in the larger community organizations. Issue-focused services (for example, in job placement and employment services, and mental health services) also cater to a cross-section of immigrants. In the smaller communities in Finland, that lack the numbers and capacity for effective subgrouping, there are indications too that alliances are being formed across groups. Such cross-group affiliation, born of necessity, could have positive impact on integration processes as well as helping to overcome, in their case, the disadvantages of numerical weakness.

From the point of view of fostering formal civil activism, a cohesive ethnic base would notnecessarily be a decisive criterion, since the required base could be built otherwise around common issues and interests, dispensing with mobilization along ethniclines. In these circumstances, group size or strongeth- nicidentification would notbe decisive. If well used, the mode of issue-focused civil and political activism could enhance participation in this sphere thus overcoming the lack of unity or numerical weight in individual communities. The role of activism in Finland otherwise still remains to be defined in a resettlement arena that is characterized by centrally and formally organized structure.

Themore centralized settlement services in Finland operate "on the ground" as part of the municipal social service units. Centralized settlement services guarantee access and consistency of service quality. Settlement service concentration within limited official channels can however, defer engagement with the wider community and lead to a prolonged period of mystification about the host society. This condition seems to be averted in the more decentralized Canadian settlement service system that comprises a spectrum of institutions and community organizations, and a plurality of service provision actors based on state and civil society institutions (e.g., community organizations and churches). The nature of resettling persons' initial interaction with service institutions and the surrounding society is thus somewhat different in the two research locations.

Data suggests that the recognition and official inclusion of diverse groups in the rhetoric and policy of multiculturalism in Canada constitutes an aspect of empowerment for resettling persons, the nation's newest citizens. Multicultural policy legitimizes in an explicit way the civil status of immigrants in Canada. In this regard, several subjects wanted to close with positive remarks about the settlement society, even though they had recounted negative or difficult experiences, for example, in the labour market. They wished to balance their responses with final remarks such as:

Canada is a good country. Anyone can study to be a doctor or lawyer, and work to get ahead. It is open for all, [and] I love Canada. It is a good place. I know I can succeed here. I am sure an opportunity will come for me.
Subjects in the Finnish target group had expressed concern over frequently encountered misunderstanding in the receiving society over their arrival and presence. They expressed the need to articulate to the public, the reason for asylum and resettlement. Lack of explicit and definitive status was perceived as giving rise to problems in the development of relations with the receiving society. Furthermore, uncertainty as to rights, duties and civil status in the receiving country constituted a source of insecurity. This reported area of unclarified status is not necessarily caused by basic difference in resettlement approach but could be a consequence of undeveloped level of policy, public debate and rhetoric. I argue that official delineation of the boundaries of inclusion in Canada, has reduced the civic vulnerability of "newcomers."

\section{Conclusion}

As a resettlement priority, employment ranked second only to family reunification. Welfare in both research sites is abuffer against the effects of unemployment among members of the labour force, but it is generally held to be a temporary measure, not an alternative income source (see Lanphier 1996). Prolonged welfare dependency provides a weak starting point for creating a role niche in resettlement society which would, on the contrary, call for strong two-way engagement and interdependence with resettlement society. Employment has become one of the main forms of interdependence in the societies of resettlement under study, being ostensibly a relationship of formal mutuality or reciprocity, in which the individual is contributing his work in return for his income. Some of the subjects saw unemployment in the context of Islamic tenets of the "right" and the "wrong," and found unacceptable the cultural impropriety of "having my hand out." A dedicated settlement worker said that he himself would not like to be in a position where he felt that the society "would be doing a kind deed by having me here." While welfare reduces the risk of poverty, there is the chance that it may at the same time, 
mask the dysfunctional aspects of unemployment on immigrant integration.

The problem of immigrant professionals' unemployment persists in both resettlement countries. This points to deep-seated structural blockage, which would call for well-orchestrated intervention. Ethnic activism should be seen however as one among several potential instruments for addressing inequality of opportunity and structurally based obstacles to participation. The resources of professionals across ethnic groups would need to be harnessed and access obtained to elite and institutional decision-making. The study findings indicate that collectively based ethnocultural activity is indeed a very effective instrument for the humane and intermediate tasks of settlement and integration. Yet the 'hard' long term issues of equality of opportunity would need to be addressed by a wideralliance base that is well integrated into the institutional structures of the resettlement society.

In this respect, key contacts and linkages would be located in the civil society arena-an area which is often largely uncharted territory for the newest citizens. Resettling individuals' and communities' engagement with civil society is an area of importance that can be overshadowed by the more compelling short-term priorities of settlement. In particular in Finland, settlement service and activity could benefit by being partially relocated into the arena of civil society if this can be achieved without compromising the social rights of resettling persons. Recurring questions of equity call for interest-based activism that can flounder without a firm base in wider civil society.

Multiculturalism in Canada, as the national policy for organizing ethnic diversity, has developed through folkloric, anti-racism, equity and empowerment phases. "Inclusion" has been high on the agenda throughoutits evolution. Finnish resettlement policy is gravitating toward a policy of multiculturalism, and has emphasized issues of tolerance, humanitarianism, and welfare state principles of citizenship rights and equity. The focus has been shifting from cultural rights and social rights, as the challenging issues of equality of opportunity bring us into the area of resettling persons' civil rights.

\section{Notes}

1. The civil arena refers to activity of associations and interest groups formed to accomplish certain goals, further certain causes or defend particular interests outside the structure of political institutions directly associated with the state (see Ghai and Hewitt de Alcántara 1994, chapter 4); the political arena refers to party and electoral activity e.g., voting, campaigning.

2. A case may be defined as a functioning specific that is bounded (Stake 1994, 236), or alternatively, as a study in which the researcher explores a single entity or phenomenon ("the case") bounded by time and activity (a program, event, process, institution, or social group) and collects detailed information by using a variety of data collection procedures during a sustained period of time (Cresswell 1994, 12; Yin 1989).

3. The terms "community" and "minority" both refer to the resettling collectivities in Canada and Finland, but "community" has fewer connotations of power relations and interest configurations. Thus either term is used according to context.

4. Quota refugees arepersons with official refugee status, who are resettled in Finland from first asylum countries or camps. Humanitarian groups refer togroups who are in need of international protection and are admitted for resettlement, although they do not strictly fit the criteria of the 1951 Convention, e.g. persons fleeing war, violence and mass persecutions. The "spontaneous" group refers to persons who seek asylum on, or after arrival in Finland, and who, on the basis of the refugee status determination procedure, are granted 1951 Convention Refugee status.

5. Purposeful sampling is a strategy in which particular settings, persons, or events are selected deliberately in order to provide important information that cannot be obtained as well from other choices. The selection of those times, settings, and individuals that can provide the researcher with the information needed in order to answer his research questions is the most important consideration in qualitative sampling decisions (Maxwell 1996, 71). Rubin and Rubin (1995, 71-76) use the term "completeness" to denote the sampling style in which the researcher sets about to "choose people who are knowl- edgeable about the subject and talk with them" until what is heard "provides an overall sense of the meaning of a concept, theme, or process."

6. Battershill (1992) points out that such systemic barriers faced by FMGs to their entrance into Canadian medicine are erected by governmental and medical policy but at the same time militate against the enactment of provincial and federal endorsements of multicultural health care. The health needs of growing numbers of immigrants and the FMG providers reflect a non-activated link of unmet demand and potential supply.

7. See also Bernstein and Shuval (1995) on professional role discontinuity of immigrant physicians to Israel.

8. See Paidar (1995) on women's formal position in nation-building and modernization processes in Iran.

9. In 1971, Prime Minister Trudeau announced the policy of multiculturalism, of which the key section was:

A policy of multiculturalism within a bilingual framework commands itself to the Government as the most suitable means of assuring the cultural freedom of Canadians. Such a policy should help to break down discriminatory attitudes and cultural jealousies. National unity, if it is to mean anything in the deeply personal sense, must be founded on confidence in one's own individual identity; out of this can grow respect for that of others and a willingness to share ideas, attitudes and assumptions. A vigorous policy of multiculturalism will help create this initial confidence. It can form the base of a society which is based on fair play for all ... The government will support and encourage the various cultures and ethnic groups that give structure and vitality to our society. They will beencouraged to share their cultural expression and values with other Canadians and so contribute to a richer life for all. (House of Commons Debates, 8 October 1971)

10. The empowerment goals set out by representatives of visible minorities are based on three institutional imperatives: access (openness to visible minorities), representation (proportionate to numbers in the population), and equity (equality of opportunity and removal of systemic barriers) (Elliot and Fleras 1990, 51-76).

11. Other studies show that women carry the main responsibility for household and children regardless of full-time employment, for example, see Thomsson (1996).

12. Citizenship is used here in the sense given by Marshall (1963) to include civil, political and social dimensions. 


\section{References}

Battershill, C. 1992. "Migrant Doctors in a Multicultural Society: Policies, Barriers, and Equity." In Deconstructing a Nation: Immigration, Multiculturalism and Racism, edited by Vic Satzewich. Social Research Unit, Department of Sociology, University of Saskatchewan.

Bernstein J. H., and J. T. Shuval. 1995. “Occupational Continuity and Change among Immigrant Physicians from the Former Soviet Union in Israel." International Migration, Quarterly Review XXXIII, no. 1, IOM.

Berry, J. W. 1996. "Prejudice, Ethnocentrism and Racism." Siirtolaisuus-Migration, no. 2/96.

Breton, R. 1992. Report of the Academic Advisory Panel on the Social and Cultural Impacts of Immigration. Canada: Research Division, Strategic Planning \& Research, Immigration Policy Group, Employment and Immigration.

Creswell, J. 1994. Research Design: Qualitative and Quantitative Approaches. London: Sage.

Elliot, J. L., and J. Fleras. 1990. "Immigration and the Canadian Mosaic." In Race and Ethnic Relations in Canada, edited by P.S. Li. Toronto: Oxford University Press.

Freire, M. 1993. "Women and Exile: A Psychological Perspective." Paper presented at the Conference on Gender Issues and Refugees: Development Implications. Centre for Refugee Studies and York Centre for Feminist Research, York University, May 9-11, 1993.

Ghai, D. and Hewitt de Alcántara, C. 1994 "Globalization and Social Integration: Patterns and Processes." Occasional Paper No. 2, World Summit for Social Development, UNRISD.

Gold, S. J. 1992. Refugee Communities: A Comparative Field Study. California: Sage Publications.
Harrell-Bond, B. E. 1986. Imposing Aid: Emergency Assistance to Refugees. Oxford University Press.

Hatch Dupree, N. 1990. "A Socio-Cultural Dimension: Afghan Women Refugees in Pakistan." In The Cultural Basis of Afghan Nationalism, edited by E. Anderson and N. Hatch Dupree. London: Pinter Publishers Ltd.

Hill Collins, P. 1990. Black Feminist Thought: Knowledge, Consciousness and the Politics of Empowerment. New York: Routledge.

Kallen, E. 1995. Ethnicity and Human Rights in Canada. Oxford University Press.

Knudsen, J-C. "Therapeutic Strategies and Strategies for Refugee Coping." Journal of Refugee Studies 4, no. 1, 21-38.

Lam, L. 1996 From being Uprooted to Surviving: Resettlement of Vietnamese-Chinese "Boat People" in Montreal, 1980-1990. Toronto: York Lanes Press.

Lanphier, C. M. 1996. "Welfare and Immigration: The Canadian Case." In Identities in Transition, edited by J. Kervinen, A. Korhonen, and K. Virtanen. Turku: Publications of the Doctoral Program on Cultural Interaction and Integration.

Lindström. V. 1995. "The Development of Multicultural Policy in Canada." In Welfare States in Trouble, edited by S. Akerman and J. L. Granatstein. Uppsala: Swedish Science Press.

Marshall, T.H. 1963. Sociology at the Crossroads and Other Essays. London: Heinemann.

Maxwell, J. A. 1996. Qualitative Research Design: An Interactive Approach. London: Sage.

McAll, C. 1990. Class, Ethnicity and Social Inequality. Montreal: McGill-Queen's University Press.

Moghadam, V. M. 1993. Modernizing Women: Gender and Social Change in the Middle East. Boulder and London: Lynne Rienner Publishers.
Obermeyer, C. M. 1995. "A Cross-cultural Perspective on Reproductive Rights." $\mathrm{Hu}$ man Rights Quarterly 7, no. 2, 366-81.

Paidar, P.1995. Women and the Political Process in Twentieth-Century Iran. Cambridge: CambridgeUniversity Press.

Rachedi, N. 1994. "Elites of Maghrebian Extraction in France." In Muslims in Europe, edited B. Lewis and D. Schnapper. London:Pinter Publishers.

Ross, M., A. Eyman, and N. Kishchuk. 1986. "Determinants of Subjective Well-Being." In Relative Deprivation and Social Comparison, edited by J. M. Olson, C. P. Herman, and M.P.Zanna. The OntarioSymposium, Vol. 4. New Jersey: Lawrence Erlbaum Associates.

Rubin H. J., and I. S. Rubin. 1995. Qualitative Interviewing: The Art of Hearing Data. London: Sage.

Stake, R. E. 1994. "Case Studies." In Handbook of Qualitative Research, edited by N. K. Denzin and Y.S. Lincoln. Thousand Oaks London:Sage.

Takalo, P., and M. Juote. 1995. Inkerinsuomalaiset. Helsinki: Ministry of Social Affairs and Health.

Thomas, D. 1994. "The Integration of Immigrants: Lessons from the Canadian Experience." In Migration and Development: New Partnerships for Co-operation, OECD, 10711.

Thomsson, H. 1996. Women's Opportunities for Well-Being: Studies of Women's work, Leisure and Health-Related Behaviour Patterns. Stockholm: Department of Psychology, Stockholm University.

Valtonen, K. 1994. "The Adaptation of Vietnamese Refugees in Finland." Journal of Refugee Studies 7, no. 1, 63-78.

Valtonen, K.1995. “Refugee Adaptation as an Experience of Stress and Coping Among the Vietnamese in Finland." Migration 26/ 94.

Yin, R. K. 1989.Case Study Research:Designand Methods. 2d ed. Newbury Park, CA: Sage. (first edition 1984).

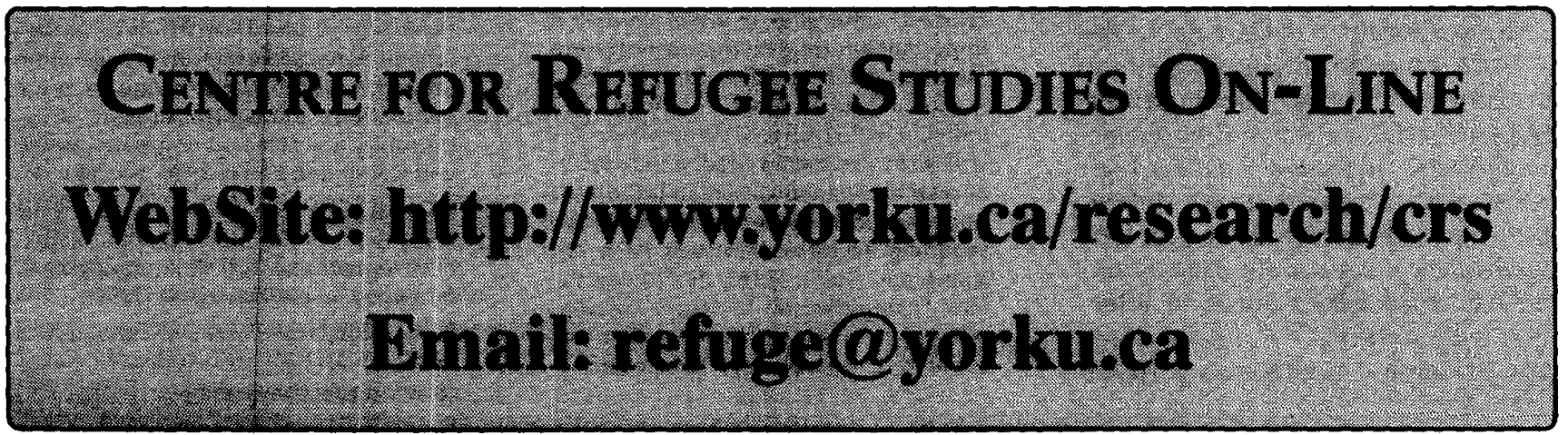




\section{CRS/YLP Publications}

\section{Books}

From Being Uprooted to Surviving: Resettlement of the Vietnamese-Chinese "Boat People" in Montréal, 1980-1990

Lawrence Lam (1996)

$\$ 18.95$

Asylum-A Moral Dilemma

W. Gunther Plaut (co-published with Praeger Publishers) (1995)

Refugee Rights: Report of a Comparative Survey James C. Hathaway and John A. Dent (1995)

Legitimate and Illegitimate Discrimination: New Issues in Migration Edited by Howard Adelman (1995)

African Refugees: Development Aid and Repatriation Edited by Howard Adelman and John Sorenson (1994) $\$ 39.90$

Immigration and Refugee Policy: Australia and Canada Compared

Edited by Howard Adelman, Lois Foster, Allan Borowski and Meyer Burstein (1994)

Volume One:

Context, Policy and Implementation

Volume Two:

Settlement and Impact

Breaking Ground: The 1956 Hungarian Immigration to Canada Edited by Robert H. Keyserlingk (1993) $\$ \$ 6.99$

Taking Refuge: Lao Buddhists in North America Penny Van Esterik (1992)

Refuge or Asylum: A Choice for Canada Edited by Howard Adelman and C. Michael Lanphier (1991)

Refugee Policy: Canada and the United States Edited by Howard Adelman (1991)

Soviet-Jewish Emigration and Resettlement in the 1990s Edited by Tanya Basok and Robert J. Brym (1991) $\$ 4.99$

\section{Reports}

Paths to Equity: Cultural, Linguistic, and Racial Diversity in Canadian Early Childhood Education Judith Bernhard, Marie Louise Lefebvre, Gyda Chud, and Rika Lange(1995) $\$ 18.95$

Cambodian Refugees in Ontario: An Evaluation of Resettlement and Adaptation

Janet McLellan (1995)

Somali Refugees in Toronto:

A Profile Edward Opoku-Dapaah (1995)

Refugee Families and Children: A Directory For Service Providers in Metro Toronto John Morris and Lydia Sawicki (1995)

Adaptation of Ghanaian Refugees in Toronto Edward Opoku-Dapaah (1993)

Report on the Workshop for African Community Groups in Toronto

Edward Opoku-Dapaah (1992)

Directory of African Community Groups in Toronto Edward Opoku-Dapaah (1992)

\section{Occasional Papers}

Fading Hopes: Struggles for Survival Among Cambodians Repatriated from Thai Refugee Camps Janet McLellan (1996)

The Genesis of a Domestic Refugee Regime: The Case of Hungary

Edited by Howard Adelman, Endre Sik and Géza Tessenyi (1994)

So That Russia Be "Saved": Anti-Jewish Violence in Russia, Its Roots and Consequences Tanya Basok and Alexander Benifand (1993)

The Refugee Crisis in Russia Rozalina Ryvkina, Rostislav Turovskiy and Robert Brym (1993)

\section{Please send your orders to:}

Centrefor RefugeeStudies Yor University

Suite 333, York Lanes, 4700 Keele Street

Toronto ON M3J 1P3

Fax: (416) 736-5663 - Email: refuge@yorku.ca or mswinder@yorku.ca http://www.yorku.ca/research/crs

Refuge, Vol. 18, No. 1 (February 1999)

(C) Kathleen Valtonen, 1999. This open-access work is licensed under a Creative Commons Attribution-NonCommercial 4.0 International License, which permits use, reproduction and distribution in any medium for non-commercial purposes, provided the original author(s) are credited and the original publication in Refuge: Canada's Journal on Refugees is cited. 


\section{REPORTS}

\section{- Somali Refugees in Toronto: \\ A Profile}

By Edward Opoku-Dapaah

ISBN 1-55014-278-x, 130 pp., \$12.95.

This is the first comprehensive study of Somali refugees in Toronto. It examines the social, residential, and linguistic characteristic of Somalis, their participation in the local economy, and the activity of Somali community organizations. The report also contains valuable suggestions and recommendations concerning suitable and more efficient service delivery to this community.

\section{- Cambodian Refugees in Ontario: \\ An Evaluation of Resettlement \\ and Adaptation}

By Janet McLellan,

ISBN 1-55014-267-4, 142 pp., \$12.95.

This major study of Cambodian refugees in Ontario examines the effects of various forms of sponsorship on Cambodian resettlement. It also focuses and the linguistic, economic, educational, training and social dimensions of the whole process of adaptation. The delivery of services by governmental and NGO agencies as well as the effects of the past traumatic experiences of genocide and mass starvation on Cambodian refugees are fully discussed.

\section{- Refugee Families and Children: \\ A Directory for Service Providers in Metro Toronto}

Compiled by

Dr. John Morris and Lydia Sawicki. ISBN 1-55014-285-2,39 pp., \$6.95.

This directory is designed for service providers who work with refugee families and children in Metro Toronto. Its aim is to improve service provision through networking and the sharing of training opportunities.

$$
\text { Available from: }
$$

\section{Centre for Refugee Studies}

Back Issues of Refuge, Canada's periodical on refugees

1. Environmental Refugees, Vol. 12, No. 1, June 1992.

2. Discussion of Immigration Bill C-86, Vol. 12, No. 2, July/(Aug.) 1992.

3. General Issue/Refugee Sponsorship, Vol. 12, No. 3, Sept. 1992.

4. Eastern European Refugees, Vol, 12, No. 4, Oct. 1992.

5. The Tragedy of Somalia, Vol. 12, No. 5, Nov./Dec. 1992

6. The Review of Rejected Refugee Claims in Canada, Vol. 12, No. 6, Jan. 1993.

7. Russia and Central Eurasia, Vol. 12, No. 7, February 1993.

8. Africa Issue: Repatriation, Vol. 12, No. 8, March 1993.

9. General Issue/Globalization, Vol. 13, No. 1, April 1993.

10. Russia and Central Eurasia, Vol. 13, No. 2, May 1993.

11. Special Issue on Sti Lanka Vol 13, No 3. June 1993.

12. Gender Issues and Refugee Law, Vol. 13, No. 4, July/Aug. 1993.

13. Southeast Asian Refugees, Vol. 13, No. 5, Sept. 1993.

14. Mozambican Refugees, Vol. 13, No. 6, October 1993.

15. Russia and Central Eurasia, Vol. 13, No. 7, Nov./Dec. 1993

16. General Issue/Sudan, Vol. 13, No. 8, January 1994.

17. Integration of Refugees-The Canadian Experience, Vol. 13, No. 9, Feb. 1994

18. Refugees and Peace in Central America, Vol. 13, No. 10, March 1994.

19. Horn of Africa, Vol. 14, No. 1, April 1994.

20. The Russian Federation, Vol. 14, No. 2, May 1994.

21. The Former Yugoslavia, Vol. 14, No. 3, June/July 1994

22. General Issue/IRB and Rebuilding Trust/Tamil Immigrants in Canada, Vol. 14, No. 4, Aug./Sept. 1994.

23. Rwandan Crisis, Vol. 14, No. 5, October 1994

24. Refugee Resettlement in Israel, Vol. 14, No. 6, Nov. 199

25. Refugee Women-Part 1: Issues, Vol. 14, No. 7, Dec. 1994

26. Refugee Women-Part 2: Case Studies, Vol. 14, No. 8, Jan. 1995.

27. The Safe Third Country Concept, Vol. 14, No. 9, February 1995.

28. Special Issue on Chechnya, Vol. 14, No. 10, March 1995

29. Reformulation of International Refugee Law, Vol. 15, No. 1, 1996

30. Environment, Development and Refugees, Vol. 15, No. 2, 1996.

31. International Intervention in Refugee Crises, Vol. 15, No. 3, 1996.

32. Early Warning on Humanitarian Crises, Vol. 15, No. 4, 1996

33. Child Refugees, Vol. 15, No. 5, 1996.

34. Global Settlement Services, Vol. 15, No. 6, 1997

35. Early Warning and Early Response, Vol. 16, No. 1, May 1997

36. Uprooting and Consequences, Vol. 16, No. 2, June 1997.

37. Development-induced Displacement, Vol. 16, No. 3, August 1997.

38. Refugee and Immigrant Women: An International Perspective, Vol. 16, No. 4 October 1997.

39. Working with Refugees and Internally Displaced Persons, Vol. 16, No. 5,

November 1997.

40. Conflict, Population Displacement, and Conflict Resolution, Vol. 16, No. 6 , .

41. Refugee and Immigrant Women: An International Perspective, Part II, Vol. 17, No. 1 February 1998.

42. Human Rights and Refugee Movements in the Newly Independent States of the Former Soviet Union, Vol. 17, No. 2, April 1998.

43. Current Issues in Refugee and Human Rights Policy and Research, Vol. 17, No. 3 , August 1998.

44. Violent Displacement and Post-Conflict Reconstruction: Afghanistan, Uganda, and Rwanda, Vol. 17, No. 4, October 1998.

45. New Cargo: The Global Business of Trafficking in Women, Vol. 17, No. 5 November 1998.

46. Critical Perspectives on Refugees, Vol. 17, No. 6, December 1998.

Single copy: Vol 12, 13 \&c14-\$6.50; Vol 15, 16, 17-\$10. 10 percent discount on 3-9 issues (copies); 20 percent discount on 10 issues (copies) or more. Special discounts are available fo students and exclusively volunteer-run NGOs. P. O. accepted.

Please send your orders to:

Centre for Refugee Studies, York University

Suite 333, York Lanes, 4700 Keele Street, Toronto, Ontario, Canada M3J 1P3 Fax: (416) 736-5837• Email: refuge@yorku.ca・mswinder@yorku.ca 


\section{Summer Course on Refugee Issues Toronto, June 6-13, 1999}

\section{Course Director: Sharryn Aiken}

The Centre for Refugee Studies' Summer Course offers postgraduate training in refugee issues for up to fifty practitioners inside and outside government who work on some aspect of refugee protection or assistance. The course includes panel discussions, case studies, a simulation exercise and lectures from international experts. A York University/Centre for Refugee Studies Certificate is awarded upon successful completion of the seven day program.

\section{Module 1: Comprehensive Overview (Five days-Monday to Friday)}

World Refugee Movements: Root Causes and Consequences • Role of the UNHCR - Law and

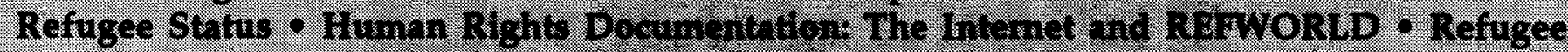
Women and Children - Intemal Dibplecenifont AProtection Regime? - Interdiction and Asylum Sharing Agreements - Impunity and the Rele of International Criminal Court - Philosophical and Ethical Perspectives - Currentroves in RefuzeePolicy:NonthemandSouthem Perspectives

\section{Module 2: Special Topics \\ (Two days-Saturday and Sunday)}

Torture, Anthropology and the Trauma of Exile; and Managing Refugee Camps a International Remedies for Refused Refugees

Fees for Full Course: \$700;

Fees for Modilie 1: \$500;

Fees for Module 2: $\$ 250$;
Late registration after March 31, 1999: $\$ 800$

Late registration after March 31, 1999: $\$ 550$

Late registration after March 31, 1999: $\$ 300$

Fees are in Canadian dollars and include materials. Food and accommodation are extra. Reasonably priced accommodation and food are available on campus. Partial subsidies are avallable for low-income participants. Limited number of internships, including full course subsidy, are available for York University students. Deadline for subsidy and internship applications is March 31, 1999.

For further information and registratton, please contact:

Shamyn Aiken, Counse Director.

Centre for Refugee Studies

Suite 329, York Lanes, York Uhiversity

4700 Keele Street, Toronto

Ontario, Canada Ms 1 1P3.

Tel.: (416) 736-2100 ext. 55423 4 I0. (416) 736-5837

Email: summeroyoukuca

(C) Kathleen Valtonen, 1999. This open-access work is licensed under a Creative Commons Attribution-NonCommercial 4.0 International License, which permits use, reproduction and distribution in any medium for non-commercial purposes, provided the original author(s) are credited and the original publication in Refuge: Canada's Journal on Refugees is cited. 
Refuge

Centre for Refugee Studies Suite 322, York Lanes York University

4700 Keele Street, Toronto Ontario, Canada M3J 1P3 Phone: (416) 736-5663 Fax:

(416) 736-5837 Email: refuge@yorku.ca

\title{
CALL FOR PAPERS
}

\section{Religious Refugees}

\section{Guest Editor: Kathryn Graham, Creative Director, MakePeace International}

This issue of Refuge will explore problem of religious refugees whose numbers are growing. For example, an estimated 200 million Christians face persecution everyday for their beliefs in many parts of the world such as Sudan, China or Indonesia. Despite the lesson of the Holocaust, many Jewish communities cannot practice their religion freely in Russia. The treatment of Baha' is in Iran is despicable. Also, some Muslims have to face discrimination and fight against very negative stereotypes, which are perpetuated even in a democratic world. Unfortunately, many governments, organizations and even academic institutions which claim to stand for and fight for human rights shy away from addressing such problems in a comprehensive manner.

Topics addressed in the issue will include the following:

- the nature of religious persecution and oppression;

- the roots and contributing factors to religious persecution, i.e., religious, racial, ethnic, historic, political, economic, etc.;

- case studies, for example, Sudan, India, China, Indonesia, Iran, Burma, Russia;

- role of international community and organizations, religious institutions, governments and NGOs in addressing this problem and accommodating religious refugees;

- possible short-term and long-term remedies; and

- Canadian response to religious persecution, both governmental and public.

Contributions with abstracts are invited. They must be received no later than August 31, 1999. Papers should be typed, doublespaced, and referenced in the approved Refuge format. They should not exceed 16 pages or about 4000 words. Short papers of about 900 words are also welcome. Word-processed submissions may be sent on disc or by e-mail.

On accepte aussi des articles en français. Le style doit conformer aux normes exigés pour les articles rédigés en anglais.

Deadline: August 31, 1999.

\author{
For further details, please contact: \\ Marek Swinder, Technical Editor, Refuge (Canada’s periodical on refugees) \\ Centre for Refugee Studies, York University, Suite 333, York Lanes \\ 4700 Keele Street, Toronto, Ontario, Canada M3J IP3
}

Fax: (416) 736-5837 - Tel.: (416) 736-5843

Email: mswinder@yorku.ca・refuge@yorku.ca 